\title{
Main Findings on Therapeutic Management of Lower Extremity Artery Disease
}

Gabriella Ricci*, Santa Carbonara and Marco Matteo Ciccone

*Department of Emergency and Organ Transplantation (DETO), Cardiovascular Diseases Section, Policlinico di Bari, University of Bari, Italy

\begin{abstract}
Atherosclerosis can involve several areas, resulting in various degrees of the vascular disease. Patients with peripheral arterial disease of the lower limbs (LEAD, lower extremity artery disease) represent a significant percentage of the vascular disease population. Therefore, the main objective of physicians who examine a patient with LEAD is to intervene on the risk factors (common to all cardiovascular diseases) using different therapeutic approaches: exercise, specific drugs and ultimately the surgical or percutaneous revascularization. The aim of this review is to summarize the key findings and the updates in the field of diagnostic methods and non- surgical therapeutic approaches for this disease.
\end{abstract}

Keywords: Lower extremity artery disease; Atherosclerosis; Functional status; Exercise; Treatment

\section{Abbrevations}

LEAD: Lower Extremity Artery Disease; REACH: Reduction of Atherothrombosis for Continued Health; CAD: Coronary Artery Disease; CVD: Cerebrovascular Disease; CLI: Critical Limb Ischemia; ALI: Acute Limb Ischemia; PAD: Peripheral Artery Disease; TREADMILL: Treatment of Peripheral Atherosclerotic Disease with Moderate or Intensive Lipid Lowering; LDL-C: Lower Density Lipoprotein- Cholesterol; UKPDS: United Kingdom Prospective Diabetes Study; VADT: Veterans Affairs Diabetes Trial; ABCD: Appropriate Blood Pressure Control in Diabetes; ACCORD: Action to Control Cardiovascular Risk in Diabetes; ABI: Ankle- brachial index; ASA: Acetylsalicylic acid; CAPRIE: Clopidogrel Versus Aspirin In Patients At Risk Of Ischaemic Events; IPC: Intermittent Pneumatic Compression; AGF: Angiogenic Growth Factors; VEGF: Vascular Endothelial Growth Factor; bFGF: basic Fibroblast Growth Factor; HGF: Hepatocyte Growth Factor; MCP-1: Monocyte Chemoattractant Protein 1; TACT: Therapeutic Angiogenesis by Cell Transplantation

\section{Introduction}

Lower extremity peripheral arterial disease (LEAD) is a condition characterized by stenosis or occlusion in the lower level of the abdominal aorta, iliac, femoral, popliteal and distal areas. Several pathophysiological processes can cause a structural alteration of the arterial wall, however atherosclerosis remains the major cause $[1,2]$. Atherosclerosis is a systemic disease that can involve several areas, not only the coronary one [3]. Given the large impact on morbidity and mortality of cardiovascular diseases [4], doctors need to assess the state of health of several vascular beds in order to establish a proper management in a vascular disease patient. The Reduction of Atherothrombosis for Continued Health (REACH) Registry reported that a significant percentage of patients with chronic coronary artery disease (CAD) suffer also from a cerebrovascular disease (CVD) and/or a LEAD [5]. The formation of fibrous-calcified deposits (atherosclerotic plaques) in LEAD determines a progressive arterial lumen narrowing with a consequent decrease of the blood flow downstream in the diseased segment [6]. LEAD may be asymptomatic or symptomatic. The symptomatic LEAD is mainly defined by the presence of muscle pain during exercise withdrawing after a short period of rest: The condition is called "intermittent claudication." We define "Critical Limb Ischemia" (CLI) the clinical condition that involves the presence of rest pain that lasts for more than 2 weeks. It regularly needs analgesic drugs and, during the clinical exam, the recorded pressure at the ankle level must be less than $50 \mathrm{mmHg}$ or less than $30 \mathrm{mmHg}$ at the first foot finger level [7]. The gradual blood supply reduction inevitably leads to anoxia, cell death with signs of evident suffering tissue (abnormal skin and appendages trophism, ulceration, necrosis and/or gangrene); the extreme consequence of CLI is the lower limb amputation [8]. Usually, CLI is characterized by the presence of chronic, continuous and resting ischemic pain, and/or by ulcers or gangrene, both caused by clinically objectified arterial occlusive disease. In patients with co-occurring disorders of the peripheral nervous system (e.g., diabetes mellitus), pain may be absent or even atypical. The definition of CLI necessarily implies chronicity of the process. It must be distinguished from acute limb ischemia (ALI) and it is applied in the presence of symptoms with onset by at least two weeks. ALI is characterized by a rapid and sudden perfusion reduction due to a local thrombotic or embolic event and can occur in the absence of a pre-existing LEAD [9]. Sudden decrease in blood flow corresponds to a new symptomatic or sudden worsening of previous symptoms and clinical signs of chronic ischemia. In this review, we will deal with the main statements on LEAD non- surgical treatment, with look at the most recent scientific evidence in drugs and emerging therapies.

\section{Treatment}

The main aim of the therapy of LEAD is to improve the overall cardiovascular risk profile and the quality of life increasing the walking distance, reducing the symptoms of claudication, eliminating pain at rest, while preserving the vitality of the limb $[1,10,11]$. The measures to be taken may be: exercise training, the use of specific drugs and revascularization (through percutaneous techniques or bypass

*Corresponding author: Gabriella Ricci, Policlinico di Bari, University of Bari, Piazza Giulio Cesare 11 Bari, Italy, Tel: +393383481664; E-mail: gabry.ricci1986@libero.it

Received July 30, 2015; Accepted August 25, 2015; Published August 31, 2015

Citation: Ricci G, Carbonara S, Ciccone MM (2015) Main Findings on Therapeutic Management of Lower Extremity Artery Disease. Cardiol Pharmacol S1: 001. doi:10.4172/2329-6607.1000001

Copyright: (c) 2015 Ricci G, et al. This is an open-access article distributed under the terms of the Creative Commons Attribution License, which permits unrestricted use, distribution, and reproduction in any medium, provided the original author and source are credited. 
surgery). Primary prevention of LEAD consists in taking measures that aim to reduce its occurrence. Typically, to counteract atherosclerotic and atherothrombotic events, physicians recommend to reduce the major cardiovascular risk factors, both with life style changes, such as stopping smoking, a healthy diet, and with pharmacological interventions, aimed at reducing hypertension or dyslipidemia. Secondary prevention intervenes, after making an early diagnosis of the atherosclerotic disease and it is designed to reduce or even stop the degenerative arterial process. In this context, specific therapies, such as antiplatelet agents, are aimed at improving the blood rheology, increasing its fluidity, determining a greater vasodilation to avoid or minimize the chronic limb ischemia, as explained below.

\section{Modification of cardiovascular risk factors}

The first intervention to be implemented in a LEAD patient is to reduce as much as possible the factors that affect its cardiovascular risk profile. This measure aims to reduce the morbidity and mortality from cardiovascular causes.

Stopping smoking is strongly recommended, since it has been shown that non-smokers or former smokers with peripheral artery disease (PAD) and PAD patients who quit smoking have a survival rate twice longer than that of patients with PAD who continue smoking [12]. The highly motivated patient can undergo behavioural therapies or use, under medical supervision, drug therapies that include bupropion, nicotine and varenicline [13-15].

The lipid-lowering treatment has a pivotal role in reducing the rate of adverse cardiovascular events. This has been demonstrated in the Heart Protection Study with a large trial involving 20,000 subjects, where treatment with simvastatin reduced the rate of cardiovascular events by $25 \%$ in atherosclerotic patients, among which 6700 were suffering from PAD [16]. An author of the study interestingly showed that less than one third of the enrolled patients were receiving appropriate lipid- lowering therapy; in addition, the trial highlighted a reduction in peripheral vascular events with statins, which has not been reported in any previous study [16]. Other studies have confirmed the protective effect of lipid-lowering therapy in patients with PAD [17]. In addition, in the TREADMILL (Treatment of Peripheral Atherosclerotic Disease with Moderate or Intensive Lipid Lowering) study it has been shown that treatment with atorvastatin $80 \mathrm{mg}$ daily significantly increased the walking distance without pain compared to placebo[18].Statins are also able to improve the lower limb functionality, increasing the walking distance and speed [19]. These findings encourage the achievement of LDL cholesterol (LDL-C) target levels in these patients at very high cardiovascular risk and, specifically, according to the latest guidelines, preferably $<70 \mathrm{mg} / \mathrm{dl}$ or, if it is not possible, a $50 \% \mathrm{LDL}-\mathrm{C}$ reduction compared to basal [20]. Unfortunately, there is poor evidence for the other currently used lipid-lowering therapies on LEAD, such as fibrates, ezetimibe and niacin [21].

Certainly, the role of antidiabetic therapy becomes predominant, since several clinical trials have shown its beneficial effect on the cardiovascular events risk $[22,23]$. In several clinical trials, in fact, it has been highlighted how the duration and severity of the diabetic disease may affect the LEAD stages [24,25]. Unfortunately, there are conflicting data regarding the effect of antidiabetic therapy on PAD, especially in patients with type 2 diabetes, such as in the UKPDS (United Kingdom Prospective Diabetes Study), where a reduction in myocardial infarction episodes (about 15\%) with insulin or sulfonylurea treatment was highlighted, without evidence of improvement in the risk of PAD incidence [26]. In particular, in another study conducted in 2005, there was no evidence of benefit from the use of pioglitazone on adverse outcomes in atherosclerotic patients, some of those with PAD [27]. Even in the VADT (Veterans Affairs Diabetes Trial) study, an intensive glucose control did not affect the primary composite endpoint of myocardial infarction, stroke, cardiovascular death, heart failure, revascularization and amputation for ischemic gangrene [28]. The current European guidelines, however, are in favour of both oral antidiabetic and insulin therapy in various formulations to counteract the adverse effects of high and uncontrolled blood sugar level on macro and microcirculation; target glycated haemoglobin levels are considered $<7 \%$ [29]. Despite the controversial data from the literature, as mentioned above, we believe that an optimal control of glucose homeostasis is of benefit for diabetic patients, because it protects them from various adverse cardiovascular outcomes.

The blood pressure control is another key element of LEAD treatment [30].In fact; the ABCD (Appropriate Blood Pressure Control in Diabetes) study demonstrated that an intensive blood pressure control is better to reduce the incidence of cardiovascular events rather than more moderate intervention [31]. However, the authors acknowledged that the study was a post hoc analysis and the number of established cardiovascular events was small. ACCORD (Action to Control Cardiovascular Risk in Diabetes) trial disagreed with the results of this study conducted in diabetic patients at high cardiovascular risk and showed no difference in terms of cardiovascular outcomes between intensive antihypertensive therapy (target $\mathrm{SBP}<120 \mathrm{~mm} \mathrm{Hg}$ ) compared to the standard (target SBP $<140 \mathrm{mmHg}$ ) [32]. Unfortunately, in a recent study conducted in 2010, the proportion of patients whose blood pressure was kept under control was lower among those with PAD than among those with CAD (coronary artery disease) or CVD (cerebrovascular disease) [33]. It would therefore be useful to promote a more effective blood pressure control in these patients to improve their outcomes and prevent complications primarily related to PAD. In addition, contrary to what was believed in the past [34], beta-blockers therapy did not lead to any significant deterioration in walking ability in a group of subjects with intermittent claudication [35]. In any case, due to the lack of studies involving large populations, it would be indicated to use this class of drugs with caution, where they are indicated. Instead, researchers have not demonstrated specific beneficial effects with the ACE inhibitors for walking distance in patients with PAD, but they encourage their use as antihypertensive drugs since they determine a prognostic cardiovascular improvement [36].

\section{Exercise therapy}

It is well established that physical therapy improves functional status in LEAD patients, their symptoms and exercise capacity [37]. In addition, it is advisable to direct the patient to a supervised exercise program rather than an uncontrolled one, since it has been demonstrated a better efficacy in terms of improvement of the maximum walking distance and cardiovascular parameters of response to exercise $[38,39]$. Generally, physical training programs last three months, with 3 weekly sessions lasting 30-60 minutes each and with a gradual increase in the effort intensity [40]. After the completion of an exercise training program, physicians generally recommend the patient to continue with a regular routine exercise [41]. A recent prospective study including 47 patients with intermittent claudication suggested kinesitherapy and electrotherapeutic procedures as alternatives to conventional nonsurgical treatment [42], opening new perspectives of research in this area. Kinesitherapy, also called "movement therapy", is a therapeutic practice mainly used for rehabilitation purposes, which, through a series of specific movements, is able to restore the function of individual muscles or of entire muscle groups. 


\section{Pharmacological therapy}

Over time, studies evaluating the onset of major cardiovascular events in patients with PAD have found that despite the correction of cardiovascular risk factors a high degree of progression of the disease to more serious stages still exists. This suggests that risk factors reduction alone is insufficient in controlling the disease course; therefore, other therapeutic measures can be beneficial. Antiplatelet drugs, such as ticlopidine, clopidogrel and aspirin, are indicated for their effectiveness in reducing, significantly, the incidence of major cardiovascular events in secondary prevention of patients with atherothrombotic disease [43]; this efficacy was not confirmed in primary prevention [44]. In presence of PAD associated with type 2 diabetes, some authoritative scientific organizations recommend a widespread use of aspirin (75-162 mg/day in primary prevention; 75$250 \mathrm{mg} /$ day in secondary prevention $[29,45,46]$. In a meta-analysis (18 studies from 1966 to 2008, more than 5000 patients with LEAD), aspirin alone or combined with dipyridamole did not induce, in treated patients, significant effects on total or cardiovascular mortality, nor on myocardial infarction, while there was a significant reduction in the incidence of stroke [47]. Ticlopidine is an antiplatelet agent that has demonstrated favourable effects in LEAD as it reduces the symptoms of claudication, increases the mobility and improves the ABI (anklebrachial index) [48]. Researchers also demonstrated a significant reduction in overall mortality in patients with claudication treated with ticlopidine compared to those treated with placebo, due to a marked decrease in coronary deaths [49]. In LEAD, ticlopidine (at the dosage of $250 \mathrm{mg}$ twice a day) can be considered a second choice, as an alternative to low-dose ASA (acetylsalicylic acid), in patients who experienced serious side effects from ASA or had cerebrovascular events despite antiplatelet treatment with aspirin. Clopidogrel is an antiplatelet drug structurally very similar to ticlopidine from which it differs only for the presence of a carboxymethyl group [50] in its molecule. The effectiveness of this drug was studied by a comparative study called CAPRIE (Clopidogrel Versus Aspirin In Patients At Risk Of Ischaemic Events), which compared the use of clopidogrel (at a dosage of $75 \mathrm{mg}$ daily), with ASA (325 mg daily), administered to over 19,000 patients with ascertained atherosclerotic vascular disease (recent ischemic stroke, myocardial infarction, symptomatic LEAD) [50]. This trial showed a modest difference in the effectiveness of clopidogrel compared with ASA regarding the main observed events (stroke, heart attack, vascular death), anyway a statistically significant $(\mathrm{p}=0.043)$ relative-risk reduction of $8.7 \%$ was in favour of clopidogrel (95\% Cl: 0.3-16.5).

The antatherothrombotic therapy should be associated with drugs able to improve walking capacity, and therefore blood flow. Among the most used in Europe there are:

1. Pentoxifylline, capable of improving erythrocyte deformability and of reducing the levels of fibrinogen and platelet aggregation [51].

2. Naftidrofuryl, an inhibitor of the serotonin receptor, which improves aerobic metabolism of hypoxic tissues [52].

3. Buflomedil, inhibitor of $\alpha 1$ and $\alpha 2$ adrenergic receptors, also equipped with a calcium antagonist activity [52].

4. Cilostazol, a type III phosphodiesterase inhibitor, with vasodilator and antiplatelet activity [53].

5. Propionyl-L-Carnitine, equipped with a mechanism of action favouring the metabolic clearance of the anomalous accumulation of acylcarnitine that occurs in skeletal muscle of arteriopathic patients, condition known as metabolic myopathy. Several clinical trials have demonstrated the efficacy of this drug on walking capacity and quality of life in patients with intermittent claudication, while a recent study has confirmed its efficacy in diabetic PAD patients $[54,55]$.

To date, the only FDA-approved drugs to improve the functional capacity in patients with LEAD are pentoxifylline and cilostazol. However, these drugs have demonstrated a limited ability to improve the walking autonomy of these patients [56]. In 2012, a study [57] was performed to evaluate the efficacy of pentoxifylline and cilostazol on pain symptoms during walking through advanced biomechanical analysis. The authors of this study enrolled 24 patients with intermittent claudication and evaluated the following parameters: the distance covered free from claudication, the parameters of kinematics and walking speed at the beginning and after 12 weeks of treatment with cilostazol or pentoxifylline. The authors have shown no significant improvements after 12 weeks of treatment with either cilostazol or pentoxifylline on the gait biomechanics of PAD patients during pain. Therefore, these drugs showed reduced relevance in the treatment of gait dysfunction during pain in patients with PAD. Cilostazol is indicated to improve maximal walking distances without pain in patients with intermittent claudication, who are free of pain at rest and without evidence of peripheral tissue necrosis (peripheral arterial disease Fontaine stage II). It is indicated; however, in the second line for patients whose changes in lifestyle and physical activity programs and other appropriate interventions did not improve sufficiently the symptoms of claudication.

\section{New (stem cell and gene therapy) and alternative therapies}

Despite advances in revascularization and pharmacological treatment, often physicians are unable to control the pain of a severely ischemic limb and preserve its vitality. Therefore, research is oriented towards alternative methods of treatment. Various alternative therapies, which are different from the classical ones, have been proposed for the LEAD treatment, but with unsatisfactory results. For example in 2008 it was studied the effect of Ginkgo biloba (a plant whose leaves are rich in polyphenols and flavonoids with vasoprotective properties) on covered distance in patients with LEAD [58]. In this trial, 62 adults with symptomatic LEAD were randomized to treatment with $300 \mathrm{mg}$ of Ginkgo biloba or placebo. Unfortunately, there were not statistically significant differences regarding the maximal treadmill walking time and the flow-mediated vasodilation of the brachial artery as assessed by ultrasonography.

One promising approach concerns the intermittent pneumatic compression (IPC), which determines an improvement in walking distance without claudication and the ABI after exercise [59]. Classically, this type of treatment is used in the phlebologic therapy for the treatment of venous leg ulcers, prophylaxis of deep vein thrombosis, while in lymphology it is used for the treatment of lymphedema [6062]. Its role in LEAD is promising, since it has been demonstrated its effectiveness in increasing the oxygenation of the extremities in patients with severe forms of this disease. It also promotes better hemodynamic response and improved treatment compliance by patients [63]. In addition, this treatment increases the flow at the level of the popliteal or infragenicolate arteries [64].

Recently the role of extracorporeal shockwave therapy in the treatment of LEAD has been suggested. A clinical double blind trial was conducted [65] to test the effects of the shockwave therapy on peripheral arterial circulation in patients with LEAD and $\mathrm{ABI}<0.7$. At the end of 
the treatment, which included 4 sessions of shock waves distributed in 4 weeks, the ABI values, the degree of stenosis and/or occlusion of the plaques were evaluated. Some patients have been treated in more than one area of stenosis/vascular occlusion, others only in one, for a total of 19 vascular locations in the treated group and 14 in the control group. By measuring the ratio between the brachial and the tibial systolic blood pressure, ie the ABI, in both controls and the treated subjects, it was shown that in the latter there was an increase of this value, indicative of an improvement of the disease stage. In subjects treated with shock waves, there was a discrete reduction of vascular stenosis, while in some patients it was possible to observe the recanalization of the same. Furthermore, the variation of the degree of stenosis before and after treatment between the two groups was statistically significant with a $\mathrm{p}$ value $<0.001$. The authors have also shown an improvement in pain symptoms, noting a reduction in class Fontaine after therapy in $63 \%$ of patients in the treatment group and in no case in the control group. The extracorporeal shockwave therapy in patients suffering from LEAD can be an interesting medical approach in order to improve the natural clinical history of the disease, not only responsible for an important reduction in the patients quality of life, but also for severe organ damage likely to compromise, in the latest stages, the very vitality of the affected limb. This method provides a third therapeutic weapon next to the medical and surgical one, suggested not necessarily as an alternative, but perfectly complementary with them.

Research in recent years has dealt with the development of new promoters of angiogenesis agents and stem cells stimulating the creation of collateral circulation useful to compensate the ineffective perfusion of atherosclerotic arteries. The angiogenic growth factors (AGF), especially the Vascular Endothelial Growth Factor (VEGF), the basic Fibroblast Growth Factor (bFGF) and the Hepatocyte Growth Factor (HGF) have been taken into account in several clinical trials. For example, researcher demonstrated that the intramuscular administration of gene therapy with AGF improves peripheral vascularization and symptoms in patients with severe LEAD [66-68]. Back in 1996, some authors proposed the intra-arterial administration of gene therapy with VEGF using plasmids as vectors in patients with pain at rest and/or arterial ulcers, who were not good candidates for conventional revascularization techniques [69]. Subsequently it has been proposed the use of adenovectors carrying VEGF intramuscularly injected in patients suffering from severe LEAD [70]. These were well tolerated and safe in patients with CLI undergoing a single dose of this drug [71]. In 2008, the group of Hobo proposed the transplantation of smooth muscle cells as a therapy able to release number factors in ischemic tissues, which favour the angiogenic cells migration and their integration with newly formed vessels [72]. The use of stem cells derived from bone marrow [73] or cytokines such as monocyte chemoattractant protein 1 (MCP-1) have been proposed as a viable option for the so-called "angiogenic therapy".

The first study that dealt with the long- term (3 years) safety and efficacy of angiogenic mononuclear cell transplantation derived from bone marrow was the TACT (Therapeutic Angiogenesis by Cell Transplantation) trial [74]. Involving patients with PAD and thromboangiitis obliterans (Buerger's disease), this trial showed a significant improvement in the "leg pain scale", the size of ulcers and in the walking distance free from pain that lasted for almost 2 years after therapy. In addition, the efficacy and safety of angiogenic cell transplantation was not inferior to the conventional revascularization techniques. The use of stem cells has been confirmed in several clinical trials that have shown a marked improvement in ischemic symptoms and faster healing of ulcers [75].

Unfortunately, despite promising results, a recent meta-analysis has not shown any clinical benefit of gene therapy in patients with LEAD, regardless of the severity of the disease [76]. In fact, the real

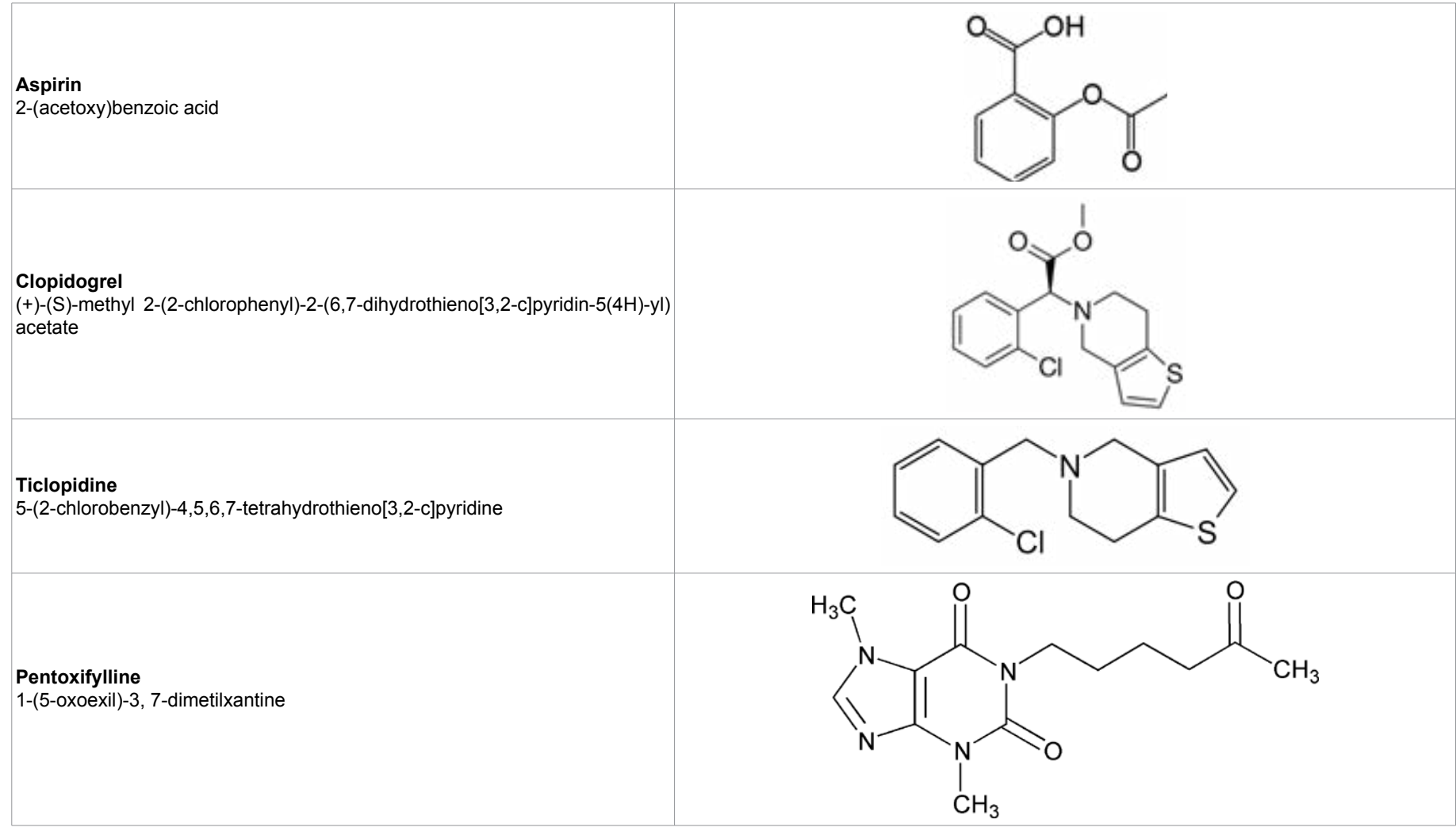


Citation: Ricci G, Carbonara S, Ciccone MM (2015) Main Findings on Therapeutic Management of Lower Extremity Artery Disease. Cardiol Pharmacol S1: 001. doi:10.4172/2329-6607.1000001

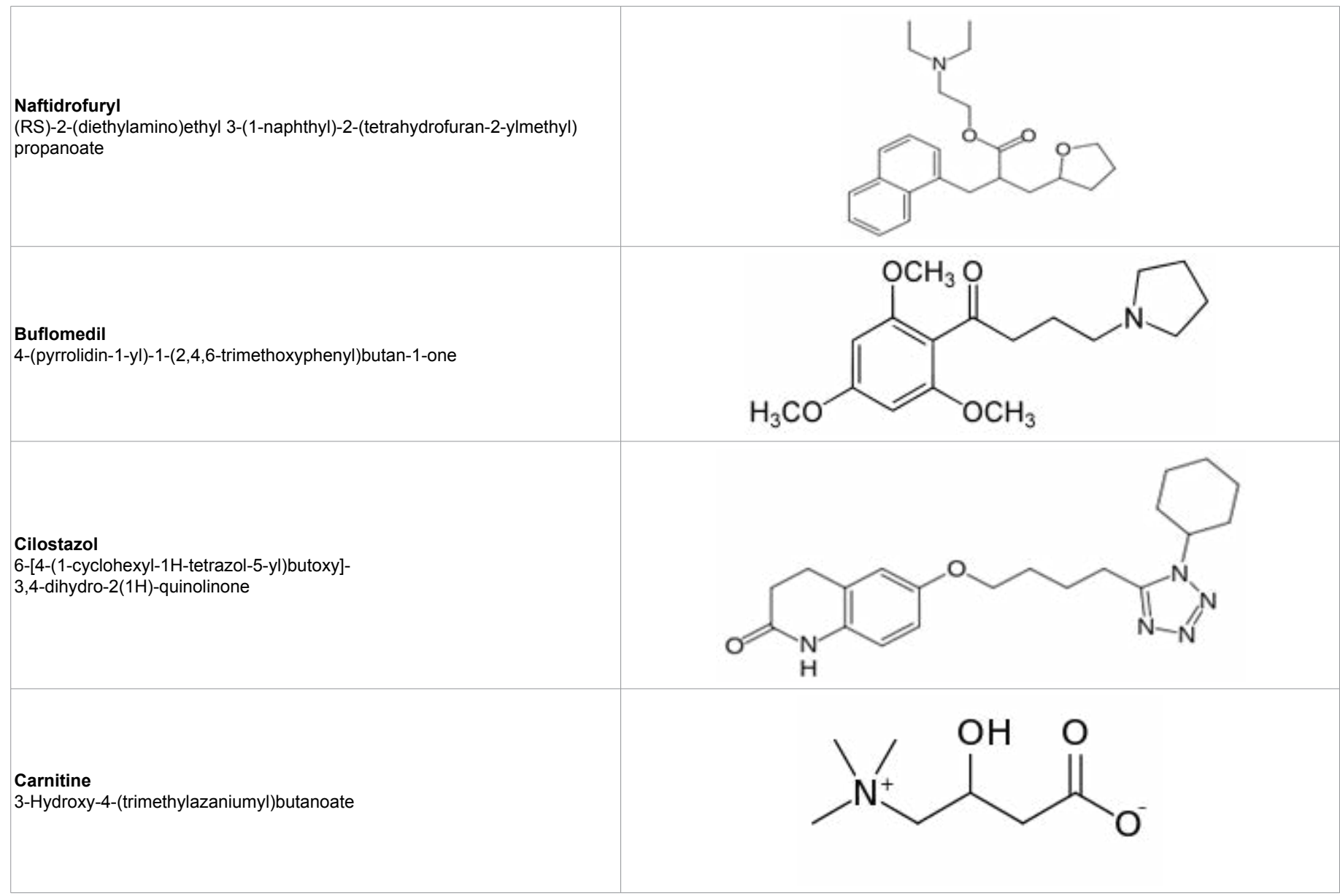

Table 1: Chemical structures of the most used drugs employed in LEAD.

mechanisms of therapeutic effect offered by stem cells are poorly understood [77-79]. Further studies will be needed to clarify this and to highlight whether there are beneficial effects on long-term functional capacity and morbidity of these patients, Table 1 .

\section{Conclusion}

The therapy of LEAD still leads to multiple development prospects. In addition to the effectiveness and efficacy of the physical therapy (controlled training programs to improve the maximal walking distance) and the usually used drugs (such as cilostazol, pentoxifylline and antiplatelet drugs), new treatments aimed at improving the functional status of these patients are recently being offered. Indeed, according to preliminary data, researchers highlighted interesting results about the use of drugs-promoting angiogenesis and stem cells. Further study will be useful, especially clinical trials involving larger patient populations to confirm these results.

\section{Acknowledgement}

The authors thank Dr. Giuliana Benedetto for her great contribution in developing the English version of this manuscript.

\section{References}

1. Rooke TW, Hirsch AT, Misra S, Sidawy AN, Beckman JA, et al. (2011) 2011 ACCF/AHA focused update of the guideline for the management of patients with peripheral artery disease (updating the 2005 guideline). Vasc Med 16: 452-476

2. Norgren L, Hiatt WR, Dormandy JA, Nehler MR, Harris KA, et al. (2007) InterSociety Consensus for the Management of Peripheral Arterial Disease (TASC
II). J Vasc Surg 45 Suppl S: S5-67.

3. Libby P (2005) Act local, act global: Inflammation and the multiplicity of "vulnerable" coronary plaques. J Am Coll Cardiol 45: 1600-1602.

4. 2012 European Cardiovascular Disease Statistics.

5. Steg PG, Bhatt DL, Wilson PW, D'Agostino R Sr, Ohman EM, et al. (2007) Oneyear cardiovascular event rates in outpatients with atherothrombosis. JAMA 297: 1197-1206.

6. Hiatt WR, Goldstone J, Smith SC Jr, McDermott M, Moneta G, et al. (2008) Atherosclerotic Peripheral Vascular Disease Symposium II: Nomenclature for vascular diseases. Circulation 118: 2826-2829.

7. Gulati A, Botnaru I, Garcia LA (2015) Critical limb ischemia and its treatments a review. J Cardiovasc Surg (Torino) 56: 775-785.

8. Blecha MJ (2013) Critical limb ischemia. Surg Clin North Am 93: 789-81.

9. Brearley S (2013) Acute leg ischaemia. BMJ.

10. Tendera M, Aboyans V, Bartelink ML, Baumgartner I, Clément D, et al. (2011) ESC Guidelines on the diagnosis and treatment of peripheral artery diseases: Document covering atherosclerotic disease of extracranial carotid and vertebral, mesenteric, renal, upper and lower extremity arteries: the Task Force on the Diagnosis and Treatment of Peripheral Artery Diseases of the European Society of Cardiology (ESC). Eur Heart J 32: 2851-2906.

11. Layden J, Michaels J, Bermingham S, Higgins B; Guideline Development Group (2012) Diagnosis and management of lower limb peripheral arterial disease: Summary of NICE guidance. BMJ 345: e4947.

12. Lu JT, Creager MA (2004) The relationship of cigarette smoking to peripheral arterial disease. Rev Cardiovasc Med 5: 189-193. 
Citation: Ricci G, Carbonara S, Ciccone MM (2015) Main Findings on Therapeutic Management of Lower Extremity Artery Disease. Cardiol Pharmacol S1: 001. doi:10.4172/2329-6607.1000001

Page 6 of 7

13. Cahill K, Stevens S, Perera R, Lancaster T (2013) Pharmacological interventions for smoking cessation: An overview and network meta-analysis. Cochrane Database Syst Rev 5: CD009329.

14. Crooks PA, Bardo MT, Dwoskin LP (2014) Nicotinic receptor antagonists as treatments for nicotine abuse. Adv Pharmacol 69: 513-551.

15. Hughes JR, Stead LF, Hartmann-Boyce J, Cahill K, Lancaster T (2014) Antidepressants for smoking cessation. Cochrane Database Syst Rev 1: CD000031.

16. Heart Protection Study Collaborative Group (2007) Randomized trial of the effects of cholesterol-lowering with simvastatin on peripheral vascular and other major vascular outcomes in 20,536 people with peripheral arterial disease and other high-risk conditions. J Vasc Surg 45: 645-654.

17. Aung PP, Maxwell HG, Jepson RG, Price JF, Leng GC (2007) Lipid-lowering for peripheral arterial disease of the lower limb. Cochrane Database Syst Rev.

18. Mohler ER 3rd, Hiatt WR, Creager MA (2003) Cholesterol reduction with atorvastatin improves walking distance in patients with peripheral arterial disease. Circulation 108: 1481-1486.

19. McDermott MM, Guralnik JM, Greenland P, Pearce $\mathrm{WH}$, Criqui $\mathrm{MH}$, et al. (2003) Statin use and leg functioning in patients with and without lowerextremity peripheral arterial disease. Circulation 107: 757-761.

20. Tendera $M$, Aboyans $V$, Bartelink $M L$, Baumgartner $I$, Clément $D$, et al (2011) ESC Guidelines on the diagnosis and treatment of peripheral artery diseases: Document covering atherosclerotic disease of extracranial carotid and vertebral, mesenteric, renal, upper and lower extremity arteries: The Task Force on the Diagnosis and Treatment of Peripheral Artery Diseases of the European Society of Cardiology (ESC). Eur Heart J 32: 2851-2906.

21. Hermans MP (2011) Non-invited review: Prevention of micro vascular diabetic complications by fenofibrate: Lessons from FIELD and ACCORD. Diab Vasc Dis Res 8: 180-189.

22. Nathan DM, Cleary PA, Backlund JY, Genuth SM, Lachin JM, et al. (2005) Diabetes Control and Complications Trial/Epidemiology of Diabetes Interventions and Complications (DCCT/EDIC) Study Research Group. Intensive diabetes treatment and cardiovascular disease in patients with type 1 diabetes. N Engl J Med 353: 2643-2653.

23. Nathan DM, Lachin J, Cleary P, Orchard T, Brillon DJ, et al. (2003) Diabetes Control and Complications Trial; Epidemiology of Diabetes Interventions and Complications Research Group. Intensive diabetes therapy and carotid intimamedia thickness in type 1 diabetes mellitus. N Engl J Med 348: 2294-2303.

24. Criqui MH (2001) Peripheral arterial disease-epidemiological aspects. Vasc Med 6: 3-7.

25. Fowkes FG, Housley E, Riemersma RA, Macintyre CC, Cawood EH, et al. (1992) Smoking, lipids, glucose intolerance, and blood pressure as risk factors for peripheral atherosclerosis compared with ischemic heart disease in the Edinburgh Artery Study. Am J Epidemiol 135: 331-340.

26. Holman RR, Paul SK, Bethel MA, Matthews DR, Neil HA (2008) 10-year followup of intensive glucose control in type 2 diabetes. N Engl J Med 359: 15771589.

27. Dormandy JA, Charbonnel B, Eckland DJ, Erdmann E, Massi-Benedetti M, et al. (2005) Secondary prevention of macro vascular events in patients with type 2 diabetes in the PROactive Study (PROspective pioglitAzone Clinical Trial In macro Vascular Events): A randomised controlled trial. Lancet 366: 1279-1289.

28. Duckworth W, Abraira C, Moritz T, Reda D, Emanuele N, et al. (2009) Glucose control and vascular complications in veterans with type 2 diabetes. $\mathrm{N}$ Engl J Med 360: 129-139.

29. Rydén L, Grant PJ, Anker SD, Berne C, Cosentino F, et al. (2013) ESC Guidelines on diabetes, pre-diabetes, and cardiovascular diseases developed in collaboration with the EASD: the Task Force on diabetes, pre-diabetes, and cardiovascular diseases of the European Society of Cardiology (ESC) and developed in collaboration with the European Association for the Study of Diabetes (EASD). European Heart Journal 34: 3035-3087.

30. Lane DA, Lip GY (2013) Treatment of hypertension in peripheral arterial disease. Cochrane Database Syst Rev.

31. Mehler PS, Coll JR, Estacio R, Esler A, Schrier RW, et al. (2003) Intensive blood pressure control reduces the risk of cardiovascular events in patients with peripheral arterial disease and type 2 diabetes. Circulation 107: 753-756.

32. ACCORD Study Group, Cushman WC, Evans GW, Byington RP, Goff DC Jr, et al. (2010) Effects of intensive blood-pressure control in type 2 diabetes mellitus N Engl J Med 362: 1575-1585.

33. Mechtouff L, Touzé E, Steg PG, Ohman EM, Goto S, et al. (2010) Worse blood pressure control in patients with cerebrovascular or peripheral arterial disease compared with coronary artery disease. J Intern Med 267: 621-633.

34. George CF (1974) Beta-receptor blocking agents. Prescribers Journal 14: 9398.

35. Paravastu SC, Mendonca DA, Da Silva A (2013) Beta blockers for peripheral arterial disease. Cochrane Database Syst Rev.

36. Bogaert MG, Clement DL (1984) Lack of influence of propranolol and metoprolo on walking distance in patients with chronic intermittent claudication. Eur Heart J 4: 203-204.

37. Shahin Y, Mazari F, Chetter I (2011) Do angiotensin converting enzyme inhibitors improve walking distance in patients with symptomatic lower limb arterial disease? A systematic review and meta-analysis of randomised controlled trials. Int J Surg 9: 209-213.

38. Watson L, Ellis B, Leng GC (2008) Exercise for intermittent claudication. Cochrane Database Syst Rev.

39. Bendermacher BL, Willigendael EM, Teijink JA, Prins MH (2006) Supervised exercise therapy versus non-supervised exercise therapy for intermittent claudication. Cochrane Database Syst Rev.

40. Hodges LD, Sandercock GR, Das SK, Brodie DA (2008) Randomized controlled trial of supervised exercise to evaluate changes in cardiac function in patients with peripheral atherosclerotic disease. Clin Physiol Funct Imaging 28: 32-37.

41. Hiatt WR, Wolfel EE, Meier RH, Regensteiner JG (1994) Superiority of treadmill walking exercise versus strength training for patients with peripheral arterial disease. Implications for the mechanism of the training response. Circulation 90: 1866-1874.

42. Kashyap VS, Pavkov ML, Bena JF, Sarac TP, O'Hara PJ, et al. (2008) The management of severe aortoiliac occlusive disease: endovascular therapy rivals open reconstruction. J Vasc Surg 48: 1451-1457, 1457.

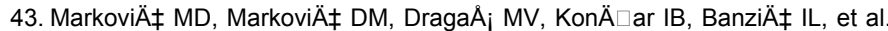
(2015) The role of kinesitherapy and electrotherapeutic procedures in nonoperative management of patients with intermittent claudication. Vascular.

44. Antithrombotic Trialists' Collaboration (2002) Collaborative meta-analysis of randomised trials of antiplatelet therapy for prevention of death, myocardial infarction, and stroke in high risk patients. BMJ 324: 71-86.

45. Antithrombotic Trialists' (ATT) Collaboration (2009) Aspirin in the primary and secondary prevention of vascular disease: Collaborative meta-analysis of individual participant data from randomised trials. Lancet 373: 1849-60.

46. Buse JB, Ginsberg HN, Barkis GL, Clark NG, Costa F, et al. (2007) Primary prevention of cardiovascular diseases in people with diabetes mellitus: a scientific statement from the American Heart Association and the American Diabetes association. Diabetes Care 30: 162-172.

47. Sobel M, Verhaeghe R; American College of Chest Physicians; American College of Chest Physicians (2008) Antithrombotic therapy for peripheral artery occlusive disease: American College of Chest Physicians Evidence-Based Clinical Practice Guidelines ( $8^{\text {th }}$ Edition). Chest 133: 815S-843S.

48. Berger JS, Krantz MJ, Kittelson JM, Hiatt WR (2009) Aspirin for the prevention of cardiovascular events in patients with peripheral artery disease: a metaanalysis of randomized trials. JAMA 301: 1909-1919.

49. Arcan JC, Panak E (1989) Ticlopidine in the treatment of peripheral occlusive arterial disease. Semin Thromb Hemost 15: 167-170.

50. Balsano F, Coccheri S, Libretti A, Nenci GG, Catalano M, et al. (1989) Ticlopidine in the treatment of intermittent claudication: A 21-month doubleblind trial. J Lab Clin Med 114: 84-91.

51. Janzon L, Bergqvist D, Boberg J, Boberg M, Eriksson I, et al. (1990) Prevention of myocardial infarction and stroke in patients with intermittent claudication effects of ticlopidine. Results from STIMS, the Swedish Ticlopidine Multicentre Study. J Intern Med 227: 301-308

52. CAPRIE Steering Committee (1996) A randomised, blinded, trial of clopidogre versus aspirin in patients at risk of ischaemic events (CAPRIE). CAPRIE Steering Committee. Lancet 348: 1329-1339. 
Citation: Ricci G, Carbonara S, Ciccone MM (2015) Main Findings on Therapeutic Management of Lower Extremity Artery Disease. Cardiol Pharmacol S1: 001. doi:10.4172/2329-6607.1000001

Page 7 of 7

53. Andreozzi GM, Arosio E, Martini R, Verlato F, Visonà A (2008) Consensus document on intermittent claudication from the Central European Vascular Forum $1^{\text {st }}$ edition - Abano Terme (Italy) - May $20052^{\text {nd }}$ revision - Portroz (Slovenia) September 2007. Int Angiol 27: 93-113.

54. Andreozzi GM (2001)Terapia medica delle ischemie croniche degli arti inferiori. In: Benedetti Valentini $F$ (eds) Chirurgia vascolare. Textbook della Società Italiana di Chirurgia Vascolare ed Endovascolare. Torino: Minerva Medica.

55. Biscetti F, Ferraccioli G, Flex A (2015) New therapeutic effects of cilostazol in patients with ischemic disorders. Curr Vasc Pharmacol 13: 399-404.

56. Brevetti G, Diehm C, Lambert D (1999) European multicentre study on propionyl-L-carnitine in intermittent claudication. J Am Coll Cardiol 34: 16181624.

57. Santo SS, Sergio N, Luigi DP, Giuseppe M, Margherita F, et al. (2006) Effect of PLC on functional parameters and oxidative profile in type 2 diabetesassociated PAD. Diabetes Res Clin Pract 72: 231-237.

58. Miller SJ, Unthank JL (2015) Understanding the role of antioxidant therapy for intermittent claudication; Good, bad, or both? Am J Physiol Heart Circ Physiol.

59. Yentes JM, Huisinga JM, Myers SA, Pipinos II, Johanning JM, et al. (2012) Pharmacological treatment of intermittent claudication does not have a significant effect on gait impairments during claudication pain. J Appl Biomech 28: 184-191.

60. Gardner CD, Taylor-Piliae RE, Kiazand A, Nicholus J, Rigby AJ, et al. (2008) Effect of Ginkgo biloba (EGb 761) on treadmill walking time among adults with peripheral artery disease: a randomized clinical trial. $\mathrm{J}$ Cardiopulm Rehabil Prev 28: 258-265.

61. de Haro J, Acin F, Florez A, Bleda S, Fernandez JL (2010) A prospective randomized controlled study with intermittent mechanical compression of the calf in patients with claudication. J Vasc Surg 51: 857-862.

62. Gould MK, Garcia DA, Wren SM, Karanicolas PJ, Arcelus JI, et al. (2012) Prevention of VTE in Nonorthopedic Surgical Patients: Antithrombotic Therapy and Prevention of Thrombosis, $9^{\text {th }}$ ed: American College of Chest Physicians Evidence-Based Clinical Practice Guidelines. Chest 141: e227S-e277S

63. Domeij-Arverud E, Labruto F, Latifi A, Nilsson G, Edman G, et al. (2015) Intermittent pneumatic compression reduces the risk of deep vein thrombosis during post-operative lower limb immobilisation: A prospective randomised trial of acute ruptures of the Achilles tendon. Bone Joint J 97-B: 675-680.

64. Zaleska M, Olszewski WL, Cakala M (2015) Intermittent Pneumatic Compression Enhances Formation of Edema Tissue Fluid Channels in Lymphedema of Lower Limbs. Lymphat Res Biol 13: 146-153.

65. Manfredini F, Malagoni AM, Felisatti M, Mandini S, Lamberti N, et al. (2014) Acute oxygenation changes on ischemic foot of a novel intermittent pneumatic compression device and of an existing sequential device in severe peripheral arterial disease. BMC Cardiovasc Disord 14: 40.
66. Labropoulos N, Wierks C, Suffoletto B (2002) Intermittent pneumatic compression for the treatment of lower extremity arterial disease: A systematic review. Vasc Med 7: 141-148.

67. Ciccone MM, Notarnicola A, Scicchitano P, Sassara M, Carbonara S, et al. (2012) Shockwave therapy in patients with peripheral artery disease. Adv Ther 29: 698-707.

68. Mikroulis D, Papanas N, Maltezos E, Bougioukas G (2007) Angiogenic growth factors in the treatment of peripheral arterial disease. Curr Vasc Pharmacol 5 : 195-209.

69. Tanaka M, Taketomi K, Yonemitsu Y (2014) Therapeutic angiogenesis: Recent and future prospects of gene therapy in peripheral artery disease. Curr Gene Ther 14: 300-308.

70. Sanada F, Taniyama Y, Azuma J, Yuka II, Kanbara Y, et al. (2014) Therapeutic Angiogenesis by Gene Therapy for Critical Limb Ischemia: Choice of Biological Agent. Immunol Endocr Metab Agents Med Chem 14: 32-39.

71. Isner JM, Walsh K, Symes J, Pieczek A, Takeshita S, et al. (1996) Arterial gene transfer for therapeutic angiogenesis in patients with peripheral artery disease. Hum Gene Ther 7: 959-988.

72. Rasmussen HS, Rasmussen CS, Macko J (2002) VEGF gene therapy for coronary artery disease and peripheral vascular disease. Cardiovasc Radiat Med 3: 114-117.

73. Mohler ER $3^{\text {rd }}$ Rajagopalan S, Olin JW, Trachtenberg JD, Rasmussen H, et al. (2003) Adenoviral-mediated gene transfer of vascular endothelial growth factor in critical limb ischemia: safety results from a phase I trial. Vasc Med 8: 9-13.

74. Hobo K, Shimizu T, Sekine H, Shin'oka T, Okano T, et al. (2008) Therapeutic angiogenesis using tissue engineered human smooth muscle cell sheets. Arterioscler Thromb Vasc Biol 28: 637-643.

75. Lachmann N, Nikol S (2007) Therapeutic angiogenesis for peripheral artery disease: stem cell therapy. Vasa 36: 241-251.

76. Matoba S, Tatsumi T, Murohara T, Imaizumi T, Katsuda Y, et al. (2008) Long-term clinical outcome after intramuscular implantation of bone marrow mononuclear cells (Therapeutic Angiogenesis by Cell Transplantation [TACT] trial) in patients with chronic limb ischemia. Am Heart J 156: 1010-1018.

77. Lee KB, Kim DI (2009) Clinical application of stem cells for therapeutic angiogenesis in patients with peripheral arterial disease. Int J Stem Cells 2 11-17.

78. Hammer A, Steiner S (2013) Gene therapy for therapeutic angiogenesis in peripheral arterial disease - A systematic review and meta-analysis of randomized, controlled trials. Vasa 42: 331-339.

79. Botham CM, Bennett WL, Cooke JP (2013) Clinical trials of adult stem cel therapy for peripheral artery disease. Methodist Debakey Cardiovasc J 9: 201 205 